\title{
Co-existence of persistent primitive trigeminal artery and another primitive carotid-basilar anastomosis associated with segmental agenesis of the ipsilateral internal carotid artery: a case report
}

\author{
Kenyu Hayashi ${ }^{1 *}$, Akihito Hashiguchi ${ }^{2}$, Koichi Moroki ${ }^{2}$, Hajime Tokuda ${ }^{2}$ and Shigetoshi Yano ${ }^{1}$
}

\begin{abstract}
Background: Embryologically, the internal carotid artery (ICA) is comprised of seven segments, any of which may be absent. We presented a very rare case of a well-preserved persistent primitive trigeminal artery (PTA), serving as a collateral pathway to the distal internal carotid artery territory, associated with segmental agenesis of the ipsilateral internal carotid artery.

Results: A 47-year-old woman with no relevant previous medical history came to our hospital for a brain checkup. Magnetic resonance angiography revealed focal agenesis of the right ICA involving the cervical, ascending, and horizontal intrapetrous segments. The enlarged ipsilateral PTA mainly supplied the distal segments of the ICA. There was also the possibility of the co-existence of another primitive carotid-basilar anastomosis; however, we could not pursue a detailed evaluation.

Conclusions: We report a rare case of a well-preserved PTA serving as a collateral pathway to the distal ICA territory associated with segmental agenesis of the ipsilateral ICA. Clinical and radiological follow-up are needed.
\end{abstract}

Keywords: Internal carotid artery, Primitive carotid-basilar anastomosis, Primitive trigeminal artery, Segmental agenesis

\section{Background}

Embryologically, from its origin to its termination, the internal carotid artery (ICA) consists of seven segments, comprising the cervical, ascending intrapetrous, horizontal intrapetrous, ascending foramen lacerum, horizontal intracavernous, clinoid, and terminal segments. Each segment is located between embryonic arteries or their remnants and any segment may be absent. This is referred to as focal agenesis and this anomaly usually does not significantly compromise blood supply to the brain [4]. Lee classified the collateral circulation utilized in the presence of segmental agenesis of the ICA as (1) normal

\footnotetext{
* Correspondence: hayashi_lucky@yahoo.co.jp

${ }^{1}$ Department of Neurosurgery, Kumamoto University, 1-1-1 Honjo,

Kumamoto, Kumamoto 860-8556, Japan

Full list of author information is available at the end of the article
}

anastomotic pathways through the circle of Willis, the most common form; (2) transcranial anastomoses from the external carotid artery; and (3) persistent embryonic vessels [7]. We report a patient with segmental agenesis of the ICA concomitant with an enlarged ipsilateral persistent primitive trigeminal artery (PTA) and another primitive carotid-basilar anastomosis as an infrequent collateral pathway to the distal ICA territory.

\section{Case presentation}

A 47-year-old woman with no relevant previous medical history came to our hospital for a brain checkup. Neurological examination showed no abnormalities. Magnetic resonance imaging showed the right PTA, with a flow void coursing postero-laterally between the dorsum sella and the cisternal portion of the trigeminal 


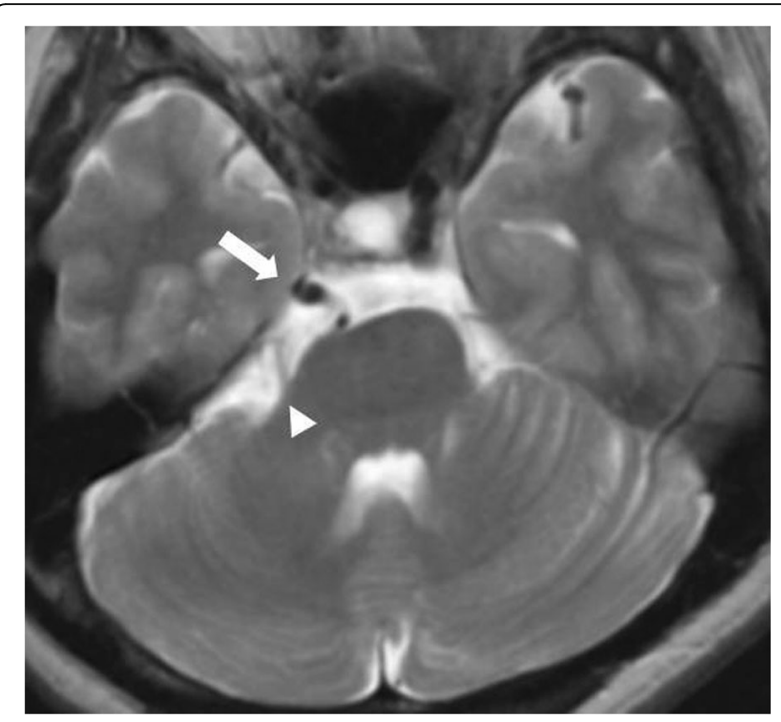

Fig. 1 Magnetic resonance imaging. Axial T2-weighted magnetic resonance imaging showing the right primitive trigeminal artery, a flow void (arrow) coursing postero-laterally between the dorsum sella and the cisternal portion of the trigeminal nerve (arrowhead)

nerve on axial T2-weighted images (Fig. 1). Magnetic resonance angiography revealed focal agenesis of the right ICA involving the cervical, ascending, and horizontal intrapetrous segments (Figs. 2 and 3). The enlarged ipsilateral PTA mainly supplied the distal segments of the ICA. The lumen of the distal ICA and its branches were normal. The ipsilateral posterior communicating artery and the A1 portion of the contralateral anterior cerebral artery were not seen (Fig. 2). The ipsilateral vertebral artery (VA) was dysplastic and appeared to arise from the ipsilateral common carotid artery (CCA; Figs. 2 and 3). The patient refused further computed tomography $(\mathrm{CT})$ and digital subtraction angiography studies.

\section{Discussion}

Primitive carotid-basilar anastomoses that may persist into adulthood, from rostral to caudal, include the trigeminal, otic, hypoglossal, and proatlantal arteries. The PTA is the most common of these, and it is angiographically detected in $0.1-0.2 \%$ of cases. It arises from the precavernous portion of the ICA, connects with the basilar artery between the anterosuperior and anteroinferior cerebellar arteries, and runs alongside with the trigeminal nerve. The PTA develops in the embryo at the 4-mm stage and connects the fetal carotid artery to the longitudinal neural artery. At the $7-12-\mathrm{mm}$ stage, the paired longitudinal neural arteries fuse into the basilar artery. The PTA begins to involute and then disappears by the 14-mm stage [5]. If the PTA persists, the basilar artery proximal to the anastomosis is usually hypoplastic. Ordinarily, the blood flow is directed from the ICA into the basilar artery. In patients with probable hemodynamic compromise of the ICA due to, for example, segmental agenesis, the blood flow to the distal ICA territory may be supplied from the vertebrobasilar system via the PTA. Such collateral pathway patterns are rare, and in our review of the literature, we found that only four cases have been described $[1,3,6]$.

In our patient, we confirmed segmental agenesis of the right ICA and a poorly developed circle of Willis. However, the presence of a well-developed ipsilateral PTA suggested that the distal portion of the ICA was primarily supplied by this vessel. The pathomechanisms of this type of collateral pathway remain to be elucidated. In our patient, there were no cardiovascular risk factors and the ipsilateral dysplastic VA appeared to communicate with the CCA. This connection might represent another primitive carotid-basilar anastomosis, such as the hypoglossal artery or proatlantal artery. We hypothesize that although the ICA developed, it regressed before involution of the PTA due to a developmental disorder
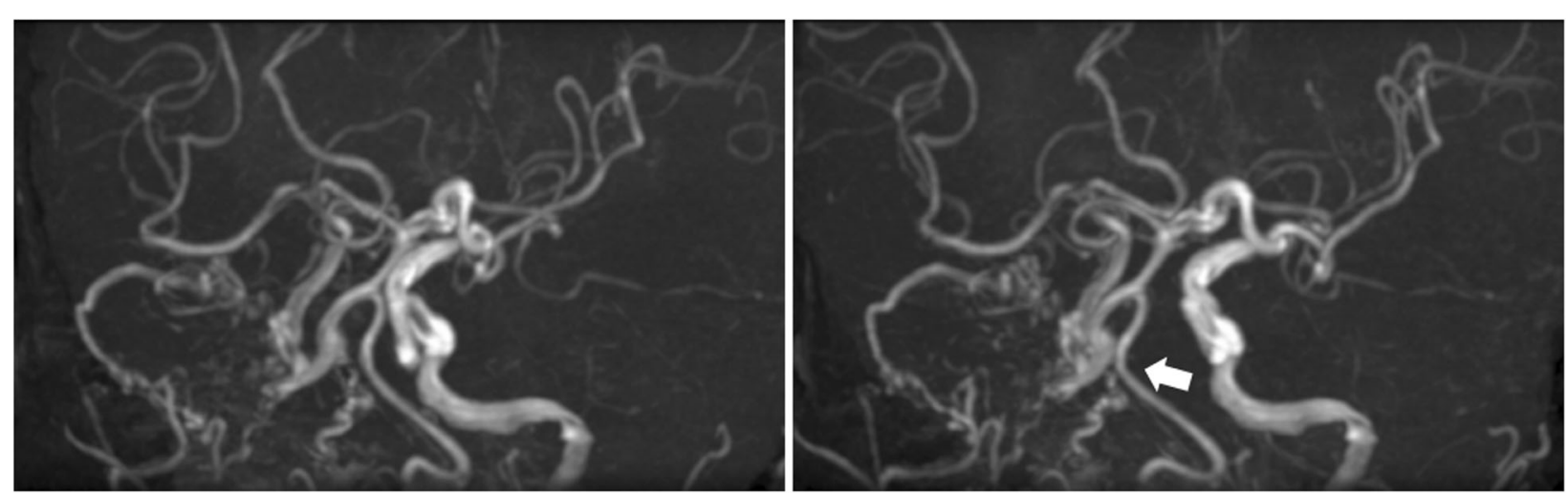

Fig. 2 Magnetic resonance angiography. Stereoscopic images of 3D time-of-flight magnetic resonance angiography showing segmental agenesis of the right internal carotid artery (ICA). The ipsilateral primitive trigeminal artery supplies the distal segments of the ICA and the dysplastic ipsilateral vertebral artery (VA). The arrow indicates the VA union 


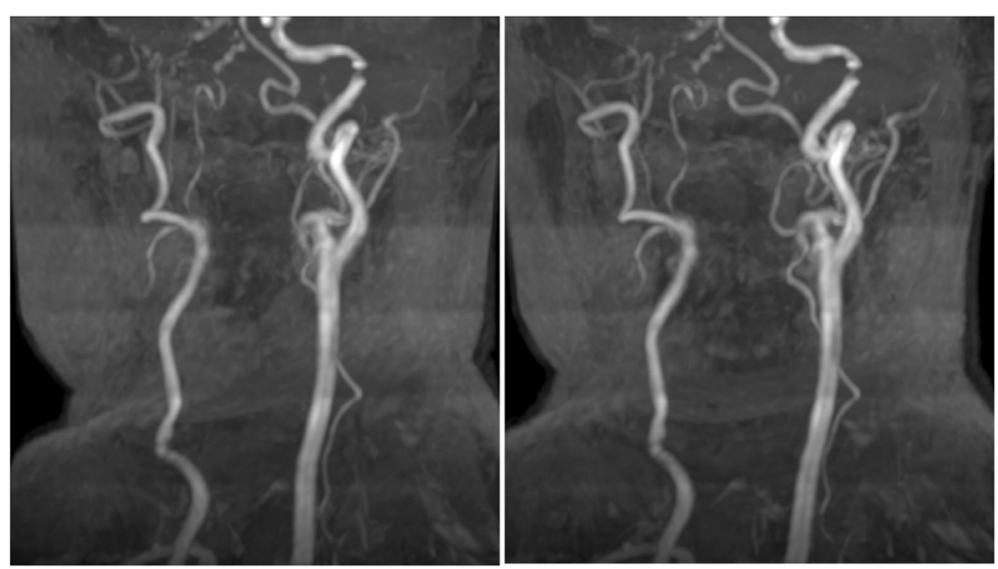

Fig. 3 Magnetic resonance angiography. Stereoscopic images of 3D time-of-flight magnetic resonance angiography showing the absence of the cervical segment of the right internal carotid artery. The ipsilateral vertebral artery appears to arise from the common carotid artery

and that this resulted in the maldevelopment of the ipsilateral ICA and VA. In our patient, the distal segments of the ICA were well-supplied by the vertebrobasilar system via the PTA. The co-existence of the PTA with other primitive carotid-basilar anastomoses is quite rare, and only a few cases have been described $[8,9]$. Furthermore, to the best of our knowledge, there are no reports of the co-existence of two primitive carotid-basilar anastomoses associated with the absence of the ICA. Although it might be another significant findings, we could not pursue a detailed evaluation. Evaluation of the carotid canal with skull base CT is valuable in differentiating congenital absence from acquired occlusion of the ICA. The absence or hypoplasia of the carotid canal suggests congenital anomalies [2]. In contrast to stenoocclusive lesions, patients with congenital absence of the ICA are usually asymptomatic for long periods due to sufficient collateral circulation. However, aneurysm and vascular compression, such as trigeminal neuralgiaenlarged collaterals, have been reported [1,2]. Thus, even in asymptomatic patients, clinical and radiological follow-ups are needed.

\section{Conclusions}

We report a rare case of a well-preserved PTA serving as a collateral pathway to the distal ICA territory associated with segmental agenesis of the ipsilateral ICA. In such cases, clinical and radiological followups are needed.

\section{Abbreviations}

CCA: Common carotid artery; CT: Computed tomography; ICA: Internal carotid artery; PTA: Primitive trigeminal artery; VA: Vertebral artery

\section{Authors' contributions}

$\mathrm{KH}$ designed the study and wrote the initial draft of the manuscript. $\mathrm{AH}$ contributed to the analysis and interpretation of the data and assisted in the preparation of the manuscript. All other authors critically reviewed the manuscript. All authors approved the final version of the manuscript and agreed to be accountable for all aspects of the work in ensuring that questions related to the accuracy or integrity of any part of the work are appropriately investigated and resolved.

\section{Consent for publication}

Written informed consent was obtained from the patient for publication of this case report and accompanying images.

\section{Competing interests}

The authors declare that they have no competing interests.

\section{Publisher's Note}

Springer Nature remains neutral with regard to jurisdictional claims in published maps and institutional affiliations.

\section{Author details}

${ }^{1}$ Department of Neurosurgery, Kumamoto University, 1-1-1 Honjo, Kumamoto, Kumamoto 860-8556, Japan. ²Department of Neurosurgery, Tokuda Neurosurgical Hospital, Kanoya, Kagoshima, Japan.

Received: 9 December 2017 Accepted: 4 April 2018

Published online: 02 May 2018

\section{References}

1. Fukuda M, Kameyama S, Takahashi H, Tanaka R. Trigeminal neuralagia caused by the vertebral artery associated with primitive trigeminal artery and agenesis of the internal carotid artery: case report. Neurol Med Chir (Tokyo). 1998;38:367-70.

2. Given CA, Huang-Hellinger F, Baker MD, Chepuri NB, Morris PP. Congenita absence of the internal carotid artery: case reports and review of the collateral circulation. Am J Neuroradiol. 2001;22:1953-9.

3. Hattori T, Kobayashi H, Inoue S, Sakai N. Persistent primitive trigeminal artery associated with absence of internal carotid artery. Surg Neurol. 1998;50:352-5.

4. Lasjaunias P, Berenstein A, Ter Brugge KG. General introduction: vascular anatomy and biological processes. In: Lasjaunias P, Berenstein A, Ter Brugge $K G$, editors. Surgical Neuroangiography, vol. 1. 2nd ed. Berlin: SpringerVerlag; 2001. p. 1-27.

5. Lasjaunias P, Berenstein A, Ter Brugge KG. The skull base and extradural arteries: the trigeminal artery. In: Lasjaunias P, Berenstein A, Ter Brugge KG, editors. Surgical neuroangiography, vol. 1. 2nd ed. Berlin: Springer-Verlag; 2001. p. 396-8. 
6. Lasjaunias P, Santoyo-Vazquez A. Segmental agenesis of the internal carotid artery: angiographic aspects with embryological discussion. Anat Clin. 1984;6:133-41.

7. Lee $\mathrm{H}, \mathrm{Oh} \mathrm{CW}$, Lee $\mathrm{SH}$, Han DH. Aplasia of the internal carotid artery. Acta Neurochir. 2003;145:117-25.

8. Tanaka Y, Hara H, Momose G, Kobayashi S, Kobayashi S, Sugita K. Proatlantal intersegmental artery and trigeminal artery associated with an aneurysm. J Neurosurg. 1983;59:520-3.

9. Uchino A, Saito N, Inoue K. Type 2 proatlantal intersegmental artery associated with persistent trigeminal artery diagnosed by MR angiography. Surg Radiol Anat. 2011;34(8):773-6.

\section{Submit your manuscript to a SpringerOpen ${ }^{\circ}$ journal and benefit from:}

- Convenient online submission

- Rigorous peer review

- Open access: articles freely available online

- High visibility within the field

- Retaining the copyright to your article

Submit your next manuscript at $\boldsymbol{\sim}$ springeropen.com 